\title{
Synthesis of zeolite $L$ using rice husk ash silica for adsorption of methylene blue: kinetic and adsorption isotherm
}

\author{
Citra Deliana Dewi Sundari ${ }^{1, *}$, Soni Setiadji ${ }^{2}$, Yusuf Rohmatullah $^{2}$, Sanusi Sanusi ${ }^{2}$, Denia Febby Nurbaeti ${ }^{2}$, Ira Novianti $^{2}$, \\ Id Farida $^{1}$, Ai Nurohmah ${ }^{2}$, and Atthar Luqman Ivansyah ${ }^{3}$ \\ ${ }^{1}$ UIN Sunan Gunung Djati Bandung, Department of Chemistry Education, Bandung, Indonesia \\ ${ }^{2}$ UIN Sunan Gunung Djati Bandung, Department of Chemistry, Faculty of Science and Technology, Bandung, Indonesia \\ ${ }^{3}$ Institut Teknologi Bandung, Master Program in Computational Science, Faculty of Mathematic and Natural Science, Bandung, \\ Indonesia
}

\begin{abstract}
Rice husk has a high silica content, so it can be utilized as silica source for zeolite synthesis. In this research, synthesis of zeolite L has been done using silica from rice husk ash without organic template. The synthesized zeolite $\mathrm{L}$ is then used as an adsorbent to adsorb methylene blue dye. The steps of zeolite $\mathrm{L}$ synthesis include: silica extraction from rice husk ash using $\mathrm{NaOH}$ and zeolite $\mathrm{L}$ synthesis using hydrothermal method with molar ratio $10 \mathrm{SiO}_{2}: \mathrm{Al}_{2} \mathrm{O}_{3}: 4 \mathrm{~K}_{2} \mathrm{O}: 100 \mathrm{H}_{2} \mathrm{O}$ at $170^{\circ} \mathrm{C}$ for 24 hours. The resulting Zeolite $\mathrm{L}$ was then characterized by XRD and SEM. The absorption capacity of methylene blue solution by zeolite L was observed experimentally through the effect of $\mathrm{pH}$ of the solution, contact time, and initial concentration of the solution, then determining the isotherm and its absorption kinetics. From XRD and SEM results of zeolite L sample, it is shown that zeolite L has been formed and its particle morphology is a hollow cylinder with cylinder diameter of $0.049-0.123 \mu \mathrm{m}$. The adsorption process refers to the Freundlich isotherm model which provides the highest correlation coefficient. The methylene blue adsorption process by zeolite L follows pseudo second-order kinetics.
\end{abstract}

\section{Introduction}

In recent years the industry is growing rapidly around the world, including in Indonesia. The negative impacts resulting from the industry are the appearance of a variety of pollutants that pollute nature, both in water, land and air. One of them is the dye waste from the textile industry. Pollutants from this industry contaminate many water sources. One of the attempts made to solve this problem is by adsorption. The adsorption process has been known as an effective method for reducing dyestuff from wastewater and is easy to handle [1]. Adsorbents are widely used because they are environmentally friendly and require a relatively low cost.

One of the most widely used adsorbents is the type of zeolite. Zeolites have molecular scale pores with sizes ranged from $3 \AA$ to $15 \AA$ which are suitable for adsorbing dyestuffs. The zeolite framework is composed of tetrahedral units $\left[\mathrm{SiO}_{4}\right]^{4-}$ and $\left[\mathrm{AlO}_{4}\right]^{5-}$ with an oxygen atom as a link between silicon and aluminum atoms that are combined in three dimensional structure [2]. There has been much research done to synthesize zeolites. It usually takes an organic template to obtain zeolite [3]. However, the use of organic templates has several disadvantages, including its toxicity, high production costs and environmental pollutions caused by the thermal decomposition of organic templates [4].

\footnotetext{
${ }^{a}$ Corresponding author: citra@uinsgd.ac.id
}

Therefore, many zeolite synthesis methods are developed without using organic template.

Typically, the silica source used for zeolite synthesis is obtained from TEOS (tetraethyl orthosilicate) [3]. But the use of TEOS is considered less economical. Several studies have used a variety of plants as an alternative source of silica, one of which is rice husks [5]. Rice husk is a waste of paddy mill that is still not utilized maximally. The silica content in rice husk ranged from 93-96\% [6]. The high silica content is the solution for the synthesis of zeolites. In addition, it is also expected to increase the selling value of rice husks. To extract the silica, a combustion is done to produce rice husk ash [7].

Several studies in the synthesis of zeolites with silica source from rice husk ash have been successfully performed. Among them are the synthesis of zeolite $\mathrm{NaA}$ at room temperature without the use of organic template [8], ZSM-5 zeolite synthesis without using organic template [9], zeolite synthesis of nano-sized particles in room temperature [10], and zeolite synthesis using hydrothermal method $[11,12]$.

In this study, silica from rice husk ash was used to synthesize zeolite L. Zeolite L also known as LTL zeolite (Linde Type L) is an environmentally friendly zeolite. The structure of zeolite L crystals was discovered by Barrer and Villager [13]. Zeolite L has one dimentional pore of about $0.71 \mathrm{~nm}$, with a $\mathrm{Si} / \mathrm{Al}$ ratio typically $0.48,1.24,1.07$. Zeolite $\mathrm{L}$ has a framework structure consisting of cancrinite (CAN) with 
a hexagonal prism (d6R) and forming a cylindrical crystal [14]. This research aimed to utilize rice husk ash for zeolite L synthesis and to investigate the synthesized zeolite $\mathrm{L}$ absorption kinetics toward methylene blue dye.

\section{Methodology}

All reagents used were analytical grade (except rice husk) and immediately used without further purification. The rice husks were separated from impurities, cleaned with distilled water, filtered and then immersed in $1 \mathrm{~N}$ $\mathrm{HCl}$ solution for 8 hours. The rice husk was then washed with $\mathrm{HCl}$ and aquades solution until the filtrate reached neutral $\mathrm{pH}$, air-dried and combusted at $700{ }^{\circ} \mathrm{C}$ for 6 hours to obtain rice husk ash. 10 grams of rice husks were dissolved in $60 \mathrm{ml}$ of distilled water and adjusted to $\mathrm{pH} 1$ using $1 \mathrm{~N} \mathrm{HCl}$. The solution was stirred for 2 hours then filtered. The residue was washed with distilled water and redissolved in $1 \mathrm{~N} \mathrm{NaOH}$ then filtered. The filtrate was rinsed using hot water then cooled and neutralized to $\mathrm{pH} 7$ using $\mathrm{HCl}$. The solution was then set for 18 hours in a polypropylene bottle until gel was formed. $100 \mathrm{ml}$ of distilled water was added to the polypropylene bottle and then centrifuged at $2500 \mathrm{rpm}$ for $15 \mathrm{~min}$, the supernatant was removed and the washing process was repeated, then dried at $80{ }^{\circ} \mathrm{C}$ until xerogel was obtained then calcined at $700{ }^{\circ} \mathrm{C}$ for 1 hour to produce silica. XRF characterization was performed to see the content of the silica.

The synthesis of zeolite $\mathrm{L}$ was done by hydrothermal method. The optimal $\mathrm{Al}_{2} \mathrm{O}_{3} / \mathrm{SiO}_{2}$ ratio for the synthesis of zeolite L was calculated based on the silica content / composition from X-ray fluorescence (XRF) characterization. The molar ratio of $\mathrm{SiO}_{2}: \mathrm{Al}_{2} \mathrm{O}_{3}: \mathrm{K}_{2} \mathrm{O}$ : $\mathrm{H}_{2} \mathrm{O}$ used was $10: 1: 4: 100$. The silicate and aluminate solutions were prepared respectively by mixing silica with $\mathrm{KOH}$ and $\mathrm{Al}(\mathrm{OH})_{3}$ with $\mathrm{KOH}$ solution. The two solutions were mixed, then heated in an autoclave at $170^{\circ} \mathrm{C}$ for 24 hours. The precipitate formed was washed with $\mathrm{DM}$ water, then heated at $80^{\circ} \mathrm{C}$ for 12 hours, until dry zeolite $\mathrm{L}$ powder was formed. Furthermore, zeolite L was characterized using XRD, SEM, and FT-IR.

In adsorption capacity test of zeolite $\mathrm{L}$ on methylene blue, it is determined the suitable adsorption kinetics, i.e., the first pseudo-first rate or second-order pseudorate. A suitable adsorption mechanism was also established, i.e., Langmuir isotherm model, Freundlich, Temkin, or Dubinin-Radukevisch. For the determination, an adsorption test was effected by $\mathrm{pH}$, contact time, and concentration. Into 6 glasses of chemicals were added 20 $\mathrm{mL}$ of methylene blue dye solution with concentration of $100 \mathrm{ppm}$, then adjusted its $\mathrm{pH}$ using $0.1 \mathrm{~N} \mathrm{HCl}$ solution with variations of $\mathrm{pH} 3,5,7,9,11$ and 13. A total of 0 , $0100 \mathrm{~g}$ zeolite $\mathrm{L}$ was added to each solution, then stirred using a rotator shaker at $150 \mathrm{rpm}$ for 30 minutes. The solution was then centrifuged at $2500 \mathrm{rpm}$ for 2 hours, the concentration of non-adsorbed dye by zeolite $\mathrm{L}$ was analyzed using UV-Vis spectrophotometer at maximum wavelength of $664 \mathrm{~nm}$. The determination of the optimum contact time was carried out in a similar way for $100 \mathrm{ppm}$ blue methylene, $\mathrm{pH} 11$, with varying stirring times of 60, 90, 120, 150, 180, 210 and $240 \mathrm{~min}$. The determination of optimum methylene blue concentration was performed by a similar procedure at $\mathrm{pH} 11$, contact time 90 minutes, with concentration variations of $10,30,50$ and $70 \mathrm{ppm}$.

The concentration of the dye in the solution and the weight of the adsorbed dye was calculated and the graph of the adsorption capacity of the dyestuff concentration was made. The amount of dye adsorbed from the solution is expressed as a heavy dyestuff adsorption capacity per zeolite $\mathrm{L}$ unit by the equation $[15,16]$ :

$$
q_{e}=\frac{\left(C_{0}-C_{e}\right) t}{m}
$$

Where:

$\mathrm{q}_{\mathrm{e}}$ : the amount of dyestuff adsorbed from the solution

$\mathrm{C}_{\mathrm{o}}$ : dye concentration before adsorption $\left(\mathrm{mg} \mathrm{L}^{-1}\right)$

$\mathrm{C}_{\mathrm{e}}$ : dye concentration after adsorption $\left(\mathrm{mg} \mathrm{L}^{-1}\right)$

$\mathrm{V}$ : solution volume (L)

$\mathrm{m}$ : mass of zeolite L (g)

\section{Results and discussions}

\subsection{Silica and Zeolite L Characteristics}

The XRF characterization result of extracted silica is presented in Table 1. The content of silica extracted from rice husk ash is $81.71 \%$ with $\mathrm{Na}_{2} \mathrm{O}$ impurity content of $5.73 \%$, and $\mathrm{Cl}$ content of $4.95 \%$. In addition, there is also LOI (loss of ignition) of $7.35 \%$. The presence of impurities, although calcined at a temperature of $700^{\circ} \mathrm{C}$, is due to the washing process of silica during the extraction process that needs to be repeated a couple of more times, where the sodium $(\mathrm{Na})$ is derived from the addition of $\mathrm{NaOH}$ to obtain sodium silicate $\mathrm{Na}_{2} \mathrm{SiO}_{3}$ in the silica extraction process from rice husk ash. The $\mathrm{Na}$ element contained in the $\mathrm{Na}_{2} \mathrm{SiO}_{3}$ solution should be lost during the addition of $\mathrm{HCl}$. It is intended to obtain pure silica in the process of forming silica gel from acidification of $\mathrm{Na}_{2} \mathrm{SiO}_{3}$ solution. In addition, the amount of LOI content is caused by incomplete combustion process.

$\mathrm{XRD}$ analysis is done to confirm the formation and crystallinity of zeolite L. The result of XRD analysis in Figure 1 shows the identification of zeolite L shown by circle marked peaks. The observation of some high intensity diffraction peaks for the zeolite L crystal structure compared to the JCPDS (Joint Committee on Powder Diffraction Standard) literature can be seen in Table 2.

Table 1. The composition of the compounds contained in the silica extracted from rice husk ash.

\begin{tabular}{|l|l|l|l|l|}
\hline Oxide & $\begin{array}{c}\text { Content } \\
(\%)\end{array}$ & Element & $\begin{array}{c}\text { Content } \\
(\%)\end{array}$ & $\begin{array}{c}\text { Deviation } \\
\text { Standard }\end{array}$ \\
\hline $\mathbf{S i O}_{2}$ & $\mathbf{8 1 . 7 1}$ & $\mathbf{S i}$ & $\mathbf{3 8 . 2}$ & $\mathbf{0 . 0 9}$ \\
\hline $\mathrm{TiO}_{2}$ & 0.0021 & $\mathrm{Ti}$ & 0.0013 & 0.0003 \\
\hline $\mathrm{Al}_{2} \mathrm{O}_{3}$ & 0.0511 & $\mathrm{Al}$ & 0.027 & 0.0014 \\
\hline $\mathrm{Fe}_{2} \mathrm{O}_{3}$ & 0.0148 & $\mathrm{Fe}$ & 0.0104 & 0.0005 \\
\hline $\mathrm{CaO}$ & 0.0479 & $\mathrm{Ca}$ & 0.0342 & 0.0017 \\
\hline $\mathrm{MgO}$ & 0.0409 & $\mathrm{Mg}$ & 0.0247 & 0.0014 \\
\hline
\end{tabular}




\begin{tabular}{|l|l|l|l|l|}
\hline $\mathrm{Na}_{2} \mathrm{O}$ & 5.73 & $\mathrm{Na}$ & 4.25 & 0.09 \\
\hline $\mathrm{K}_{2} \mathrm{O}$ & 0.0584 & $\mathrm{~K}$ & 0.0485 & 0.0024 \\
\hline $\mathrm{P}_{2} \mathrm{O}_{5}$ & 0.014 & $\mathrm{P}$ & 0.0061 & 0.0006 \\
\hline $\mathrm{SO}_{3}$ & 0.0106 & $\mathrm{~S}$ & 0.0042 & 0.0003 \\
\hline $\mathrm{LOI}$ & 7.35 & - & - & - \\
\hline $\mathrm{ZnO}$ & 0.0022 & $\mathrm{Zn}$ & 0.0018 & 0.0003 \\
\hline $\mathrm{CuO}$ & 0.0016 & $\mathrm{Cu}$ & 0.0013 & 0.0003 \\
\hline $\mathrm{Cl}$ & 4.95 & $\mathrm{Cl}$ & 4.95 & 0.11 \\
\hline
\end{tabular}

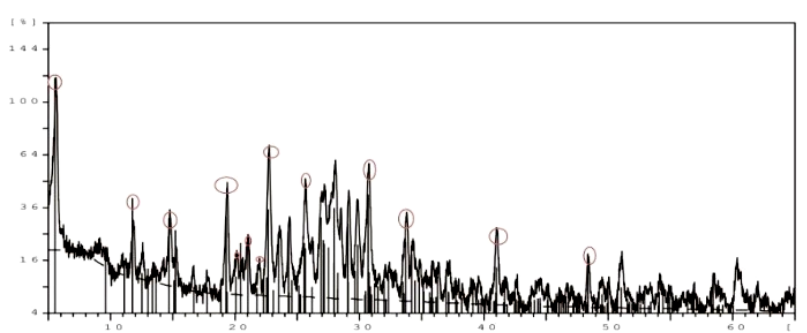

Fig. 1. XRD characterization result of zeolite L.

Table 2. The comparison of XRD data of zeolite L between JCPDS and experiment result.

\begin{tabular}{|c|c|c|}
\hline Intensity & $\begin{array}{c}2 \theta \text { of zeolite } \mathbf{L} \\
\text { (JCPDS) }\end{array}$ & $\begin{array}{c}2 \theta \text { of zeolite } L \\
\text { (experiment) }\end{array}$ \\
\hline 888 & 5.515 & 5.615 \\
\hline 149 & 11.825 & 11.865 \\
\hline 202 & 14.624 & 14.790 \\
\hline 335 & 19.976 & 19.370 \\
\hline 92 & 20.426 & 20.175 \\
\hline 154 & 22.188 & 21.070 \\
\hline 62 & 22.596 & 21.990 \\
\hline 552 & 23.276 & 22.745 \\
\hline 350 & 25.680 & 25.655 \\
\hline 48 & 37.034 & 31.585 \\
\hline 250 & 37.000 & 33.810 \\
\hline 185 & 41.108 & 41.060 \\
\hline 104 & 48.665 & 48.410 \\
\hline
\end{tabular}

Compared with the JCPDS database it can be stated that the zeolite L structure has been formed, but there are still some impurity peaks caused by less homogeneous stirring when mixing the silicate and aluminate solution. FTIR analysis on zeolite L before and after methylene blue adsorption is performed to prove the presence of a functional group binding between zeolite $\mathrm{L}$ and methylene blue dye. FTIR spectrum of zeolite L before and after absorption can be seen in figure 2 .

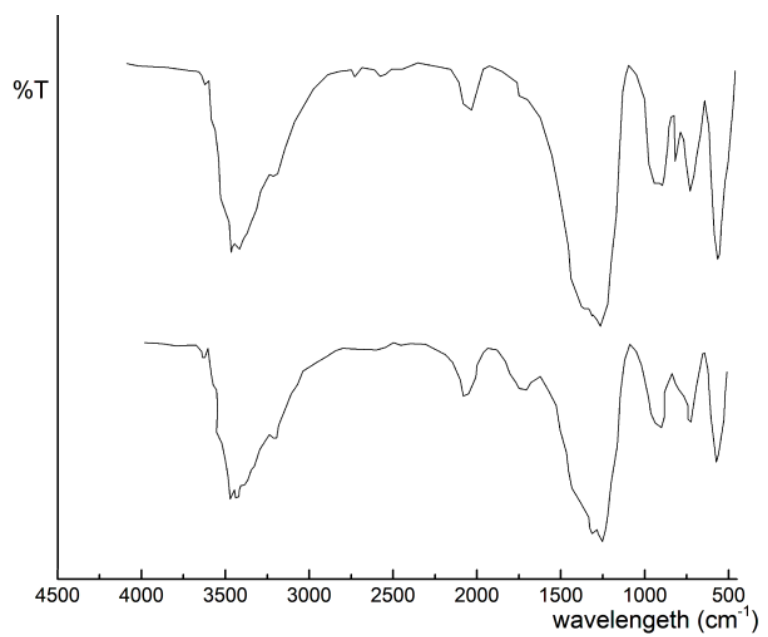

Fig. 2. FTIR spectrum of zeolite L before (top) and after adsorption (bottom).

The IR absorption of zeolite $\mathrm{L}$ before adsorption at wave number of $3525.88 \mathrm{~cm}^{-1}$ is identified as vibration of hydroxy group $(-\mathrm{OH})$ on silanol group $(\mathrm{Si}-\mathrm{OH})$, and there is no wave number shift after zeolite L adsorbs methylene blue dyestuff, the wave number value is still $3525.88 \mathrm{~cm}^{-1}$, but there is a change of absorption intensity, where the absorbance intensity percentage of silanol is decreased after zeolite $\mathrm{L}$ adsorbs blue methylene dyestuff. At the wave number of $1062.78 \mathrm{~cm}^{-1}$ before adsorption and $1097.50 \mathrm{~cm}^{-1}$ after adsorption show the vibration of $\mathrm{Si}-\mathrm{O}$ group of siloxane group ( $\mathrm{Si}-$ $\mathrm{O}-\mathrm{Si}$ ). The adsorption of blue methylene dyestuff by zeolite L is a physical adsorption (fisisorpsi), since there is no new absorption peak that shows the presence of a bond between the groups present in the methylene blue dye and the zeolite L.

SEM analysis on zeolite $\mathrm{L}$ before and after adsorption of methylene blue dye is done to determine the size and morphology of the zeolite crystal surface as methylene blue dye adsorbent. Figure 3 shows the result of SEM characterization of zeolite $\mathrm{L}$ before and after adsorption. From Figure 3 it can be concluded that the morphological form of the zeolite L particles is a hollow cylinder, where in Figure 3 (a) is zeolite L before adsorption, there are still cavities between particles of zeolite L, whereas in Figure 3 (b) which is the morphology of zeolite L after adsorption, the previously hollow cavities between particles of zeolite L, are covered by a methylene blue dye. The picture is illustrated in Figure 3 (c) with a magnification of $40,000 \times$ where the cavities between zeolite L particles are still open with cylindrical diameter of $0.049-0.123$ $\mu \mathrm{m}$. In Figure 3 (d) with a magnification of $40,000 \times$ shows that the cavities between zeolite L particles are covered by a methylene blue dye. 


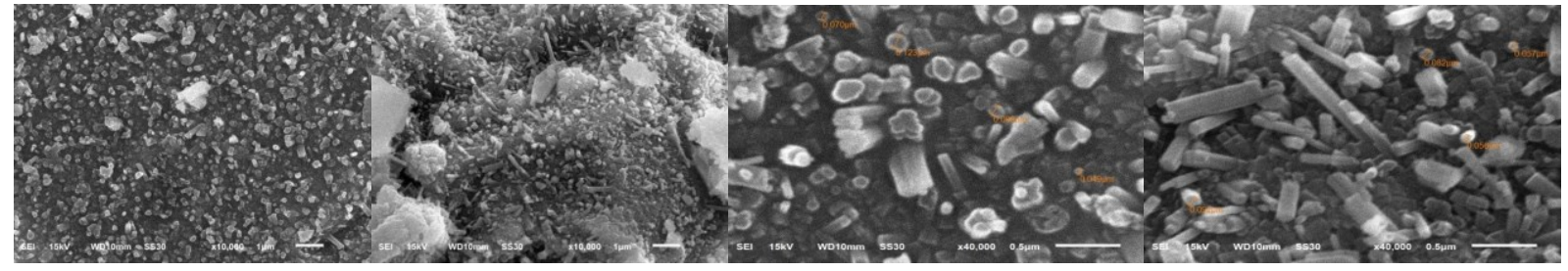

Fig. 3. SEM images of zeolit L (a) before adsorption (10.000×), (b) after adsorption (10.000×), (c) before adsorption (40.000×), (d) after adsorption $(40.000 \times)$.

\subsection{Adsorption Kinetics}

The rate of adsorption order is determined by the rate law of pseudo first- and second-order. The measurement of the adsorption rate constant for the methylene blue adsorption by zeolite $\mathrm{L}$, determined from the equation of the pseudo first-order rate law is given by the Lagegren and Svenska equation [17] :

$\ln \left(q_{e}-q_{t}\right)=\ln q_{e}-k_{l} t$

where $\mathrm{q}_{\mathrm{e}}$ and $\mathrm{q}_{\mathrm{t}}$ represent the amount of adsorbed blue methylene (mg. $\left.\mathrm{g}^{-1}\right)$ at equilibrium and time $\mathrm{t}(\mathrm{min})$ respectively, and $\mathrm{k}_{1}$ is the adsorption rate constant (g.mg$\left.{ }^{1} \cdot \mathrm{min}^{-1}\right)$.

The data of methylene blue dyestuff adsorption by zeolite $\mathrm{L}$ at various times are evaluated to obtain suitable kinetics for the adsorption system. The pseudo first-order rate curve of the above equation, $\ln \left(\mathrm{q}_{\mathrm{e}}-\mathrm{q}_{\mathrm{t}}\right)$, versus $\mathrm{t}$ is shown in Figure 4 (a). The linear regression of this curve gives a value $\left(\mathrm{R}^{2}\right)$ of 0.91 . The pseudo second-order kinetic model is expressed by following equation [18]:

$\frac{t}{Q_{t}}=\frac{1}{k_{2} Q_{\varepsilon}^{2}}+\frac{1}{Q_{\varepsilon}} \mathrm{t}$

The parameters of $\mathrm{q}_{\mathrm{e}}\left(\mathrm{mg} \cdot \mathrm{g}^{-1}\right)$ and $\mathrm{k}_{2}\left(\mathrm{~g} \cdot \mathrm{mg}^{-1} \cdot \mathrm{min}^{-1}\right)$ are calculated from the $\mathrm{t} / \mathrm{qt}$ versus $\mathrm{t}$ plot, with $\mathrm{h}=\mathrm{k}_{2} \cdot \mathrm{qe}^{2}$ $\left(\mathrm{mg} \cdot \mathrm{g}^{-1} \cdot \mathrm{min}^{-1}\right)$ is the initial rate of absorption at $\mathrm{t} \rightarrow 0$ [18]. The $t /$ qt versus $t$ plot from the above equation shown in Figure 4 (b) with linearity value $\left(R^{2}=0.994\right)$.

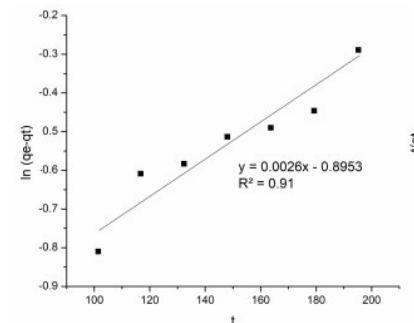

(a)

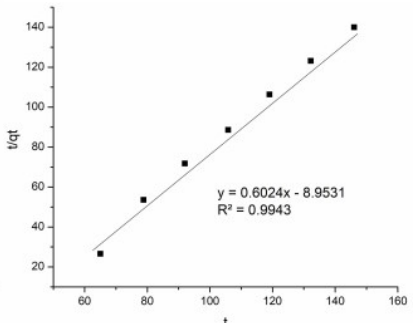

(b)
Fig. 4. Curves of adsorption kinetics (a) pseudo first-order (b) pseudo second-order.

From the curve linearity value, it can be concluded that the kinetics of methylene blue dye adsorption by zeolite $\mathrm{L}$ refers to the pseudo second-order rate. Where the value of $\mathrm{R}^{2}$ at the pseudo second-order rate has the best linearity of 0.994 . The obtained rate constant of methylene blue adsorption is $-0.041 \mathrm{~g} \mathrm{mg}^{-1} \mathrm{~s}^{-1}$. In addition, at the pseudo second-order adsorption rate the qe value from the calculation approaches the qe value of the experimental result of 1.6613 and 1.9028 respectively. The sorption rate constant for the pseudo second-order kinetic model has a small value, characterizing small activity energy on the mechanism of methylene blue sorption by zeolite L. The small activity energy characterizes that the sorption mechanism occurs by fisisorption. This is similar with the adsorption of the blue methylene dyestuff that has been conducted by previous researchers [19-21], generally the methylene blue adsorption kinetics by zeolite L refers to the pseudo second-order rate.

Isothermal adsorption types can be used to study the adsorption mechanism of blue methylene dyestuff using zeolite L at $298 \mathrm{~K}$. The adsorption capacity of zeolite L to blue methylene dyestuff can be studied by its isotherm type. In this study, comparative studies of kinetics is done with different types of isotherms, i.e., Langmuir isotherm, Freundlich isotherm, Temkin isotherm and Dubinin-Radukevisch isotherm. The linear equations of the four types of adsorption isotherms can be seen in Table 3 and their adsorption isotherm curves can be seen in Fig. 5.

Table 3. Isotherm equations.

\begin{tabular}{|c|c|}
\hline Isotherm types & Equations \\
\hline Langmuir & $1 / \mathrm{q}_{\mathrm{e}}=1 / \mathrm{Kq}_{\mathrm{m}} \mathrm{C}_{\mathrm{e}}+\left(1 / \mathrm{q}_{\mathrm{m}}\right)$ \\
\hline Freundlich & $\log \mathrm{qe}=\log \mathrm{K}+1 / \mathrm{n} \cdot \log \mathrm{Ce}$ \\
\hline Temkin & $q_{e}=\left(R T / b_{T}\right) \ln a_{T}+\left(R T / b_{T}\right) \ln C_{e}$ \\
\hline Dubinin-Radukevisch & $\ln q_{e}=K \varepsilon+\ln q_{\mathrm{D}-\mathrm{R}}$ \\
& \\
\hline
\end{tabular}

From the fourth linear curve of the adsorption isotherm it is seen that the highest linearity is achieved by the Freundlich isotherm model with $\mathrm{R}^{2}=0.981$. Therefore, the blue methylene adsorption model of zeolite L follows Freundlich's isotherm adsorption model. Freundlich isotherm is an isotherm equation which illustrates that the surface of the adsorbent is heterogeneous with a non uniform adsorption energy distribution across the entire surface of the adsorbent. The linear form of the Freundlich equation can be expressed as [22]:

$\log q_{\theta}=\log K+\frac{1}{n} \log C_{\theta}$

where $\mathrm{q}_{\mathrm{e}}$ is the adsorption capacity at equilibrium (mg. $\mathrm{g}^{-1}$ ) and $\mathrm{C}_{\mathrm{e}}$ is the concentration of methylene blue dye $\left(\mathrm{mgL}^{-1}\right), \mathrm{n}$ is the heterogeneity factor and $\mathrm{K}$ shows 
the relative adsorption capacity. The curve for the Freundlich isotherm equation is shown in Figure 5 (b).

The values of $\mathrm{n}$ and $\mathrm{K}$ are calculated from the slope and intercept of the linear plot of $\log q_{e}$ versus $\log C_{e}$ and from that data can be obtained the adsorption intensity value $\mathrm{n}=2.2936(\mathrm{n}<10)$ and the relative adsorption capacity $\mathrm{K}=1,406 \mathrm{mg} / \mathrm{g}$. This predicts that this adsorption occurs in a reversible manner with the surface of the adsorbent being heterogeneous.

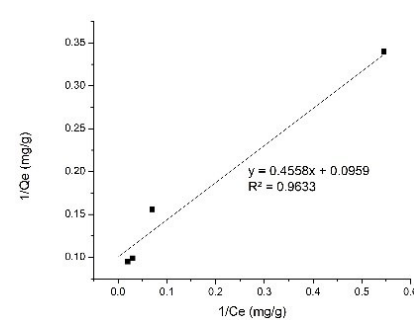

(a)
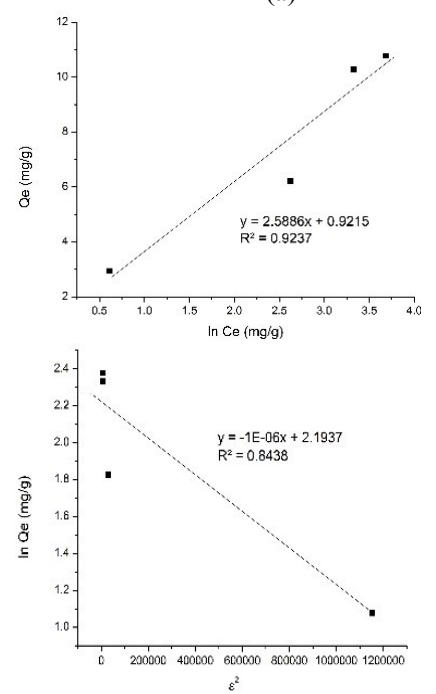

(c)

Fig. 5. Curves of adsorption isotherm models (a) Langmuir, (b) Freundlich, (c) Temkin, and (d) Dubinin-Radukevisch.

\section{Conclusion}

The silica extracted from rice husk ash was obtained with $\mathrm{SiO}_{2}$ content of $81.71 \%$. The XRD and SEM results show that zeolite $\mathrm{L}$ has been formed with a cylindrical morphology of $0.049-0.123 \mu \mathrm{m}$ in diameter. The adsorption of methylene blue by zeolite L occurs physically by following the rate law of pseudo secondorder kinetics. While the adsorption mechanism corresponds to the Freundlich isotherm model in which the surface of the adsorbent is heterogeneous and the adsorption occurs reversibly.

We acknowledge LP2M UIN Sunan Gunung Djati Bandung provided financial support.

\section{References}

1. D. Prasetyoko, Z. Ramli, S. Endud, H. Hamdan and B. Sulikowski, Waste Manage. 26, 1173-9 (2006).

2. R. E. Cooper, C. D. Andrews, P. S. Wheatley, P. B. Webb, P. Wormald and R. E. Morris, Nature. 430, 1012-6 (2004).

3. L. Tosheva and V. P. Valtchev, Chem. Mater. 17, 2494 (2005).

4. Kim. S.D, Si Hyun Noh, Jun Woo Park, Wha Jung Kim, Microporous Mesoporous Matter. 181 - 188 (2006).

5. Z. Ramli, E. Listiorini and H. Hamdan, Journal Technology. 25, 27-35 (1996).

6. Valtchev, I, V. Lasheva, Tz. Tzolov, N. Josifov, J. Chem. Tech. and Metallurgi, 44, 3, 2009, 257-261 (2009).

7. U. Kalapathy, A. Proctor and J. Shultz, Bioresource Technology. 73, 257-262 (2000).

8. Z. Ghasemi and H. Younesi, J. Nanometer. 2011 (2011).

9. Cheng, Y. Lian-Jun Wang, Jiang-Sheng Li, YuChuan Yang, Xiu-Yun Sun, Materials Letters, 59, $3427-3430$ (2005).

10. S.Mintova, N. H. Olson, V. Valtchev and T. Bein, Science. 283, 958 - 960 (1999).

11. R. M. Barrer, Academic Press. (1982).

12. Y. Watanabe, Y. Moriyoshi, Y. Suetsugu, T. Ikoma, T. Kasama, T. Hashimoto, H. Yamada and J. Tanaka, J. Am. Ceram. Soc. 87, 1395-17 (2004).

13. Yong Sig Ko and Wha Seung Ahn, Bull. Korean Chem. Soc. 202 (1999).

14. Atlas of Zeolite Framework Types: http://www.iza.structure.org (accessed October 12, 2013)〉

15. A.D. Khawaji, I.K. Kutubkhanah, J.M. Wie, Desalination 221, 47-69 (2008).

16. C. Qin, R.Wang,W. Ma, Desalination 259, 156-160 (2010)

17. Crini. G.Peindy, H.N.Gimbert, F, and Robert.C, Separation and Purification Technology 53, 97-110 (2007).

18. Gupta. S, and Babu. B.V, Chemical Engineering Journal, 150, 352-365 (2009).

19. V. Vadievelan, and K. Vasanth Kumar, Journal of Colloid and Interface Science 286, 90-100 (2005).

20. [M. Dogan, M. Alkan, A. Turkyilmaz, and Y Ozdemir, Journal of Hazardous Material B109, 141-148 (2004).

21. M. Dogan, Y. Ozdemir, and M. Alkan, Dyes and Pigment 75920070 701-713.

22. R.I. Yousef, B. El-Eswed, A.H. Al-Muhtaseb, Chem. Eng. J. 171, 1143-1149 (2011). 